\title{
Critique on Critique
}

\section{NichOLAS HOLM}

MCMASTER UNIVERSITY

Luc Boltanski

On Critique: A Sociology of Emancipation

Polity Press, Cambridge, 2011

ISBN 9780745649641

RRP \$105.00

Critique-alongside its family of relations and derivations, from criticism to critical-occupies a central position within the field of cultural studies and related humanities and social science disciplines. Critique is not simply what one does, it is also the motivation, the spirit and the goal that propels one's work, not to mention an easy-at-hand admonition to hurl at students or interlocutors ('the problem is that you're not being critical enough'). Given, then, the centrality of critique to the project of cultural studies, it may appear unfortunate, if not altogether unexpected, that the term critique itself is discussed relatively sparingly, if at all, and is almost never subject to sustained consideration or analysis. Which is to say that critique is almost never turned upon itself: critique is not subjected to critique. 
In this sense 'critique' serves a similar, though perhaps more profound, role to that of the 'institution' within sociology, which Luc Boltanski describes in On Critique as both 'one of the discipline's founding concepts: one of those it is virtually impossible to ignore' and a concept that 'is rarely the object of any attempt at definition or even specification'. (51) In identifying the institution as such, Boltanski lays the groundwork for his own fine-combed explication of the term wherein he very carefully teases out the interconnecting relations between different subdisciplinary assumptions regarding institutions, and the manner in which those assumptions reflect still useful ways for conceiving the political ebb and flow of social stability and change. In this sustained engagement with the overlooked idea of the institution, Boltanski demonstrates a dogged and methodical scholarly approach that can be taken as a model for the overall volume (the third chapter of which comprises the aforementioned examination of institutions conceived as the social antithesis of critique). In On Critique, Boltanski offers a meticulous and theoretically dense analysis of the notion of critique, as it underpins the entire sociological project, as it informs the critical sociology of Bourdieu and Boltanski's own 'pragmatic sociology of critique' as it occurs and is employed by non-sociologists in their everyday lives, and as it becomes a necessary means to engage with the structures of domination that shape contemporary democratic-capitalist societies.

Luc Boltanski lacks the recognition in the English-speaking world afforded to his teacher and erstwhile collaborator, Pierre Bourdieu. However, Boltanski's contributions to sociology are highly regarded on the continent and, indeed, On Critique began life as the 2011 series of Adorno lectures delivered at the Institute for Social Research in Frankfurt, which in past years have been delivered by notable figures such as Stephen Greenblatt and Judith Butler. The three lectures have since been substantially expanded and reworked in this volume and in their current form offer an introduction to, and brief history of, Boltanski's pragmatic sociology of critique which serves, in turn, as the basis for an elaboration of the theoretical notion of critique and its necessary political role under the conditions of neoliberal capitalism. Readers do not, therefore, need to be particularly familiar with Boltanski's oeuvre in order to appreciate the argument he offers here, which are framed in part as a series of quasi-biographical questions examining the development of his own sociological methods. 
At the heart of Boltanski's discussion of critique are several oppositions framed around the structuring question of domination. The first of these oppositions is a distinction between critical sociology and what is referred to as 'standard sociology'. (1) Critical sociology is concerned with asymmetric distributions of power that occur at the level of social totality and therefore beyond the perceptual bounds of the everyday. In order to perceive such domination, critical forms of sociology must adopt a position of exteriority from which any given arrangement of society appears as a contingent and arbitrary form-and indeed all sociology is argued to possess some degree of criticality by virtue of this founding move of exteriorisation. That Boltanski offers this aspiration towards objective externality in such an unapologetic and apparently untroubled manner speaks to the manner in which even self-declared critical sociology can remain untroubled by objections and complications raised by scholars of subjectivity in the context of cultural studies and associated disciplines. Yet, Boltanski nonetheless also explicitly rejects the quantification and de-personalisation of sociology, which he denounces as an attempt to 'dissolve the ghost of critique', (16) and instead advocates for the retention of 'judgement' of the existing social order.

Description and judgement thus compose a second opposition which in turn defines the relation between critical sociology and sociology of critique. Judgement is here understood as the means by which to identify systems of economic and semantic domination that act to perpetuate regimes of exploitation along class, race and gender lines. This tension between critical judgement and scientific description also informs Boltanski's account of the break between the critical sociology of his teacher, Bourdieu, which employs an idea of domination denounced as 'too powerful and too vague in character' (20) and his own pragmatic sociology of critique. Rejecting the notion that actors are overwhelmingly determined by the internalisation of structures and norms, and blind to the true conditions of their existence, Boltanski argues that actors are themselves capable of critique and that any sociology that fails to acknowledge this capacity will be unable to account for social change. Boltanski is at great pains, though, to make clear that this break is a methodological difference of description, rather than a political break with the desire for critique. The difference with pragmatic sociology is that it turns to social 
actors to furnish its critical thrust, rather than relying upon the sociologist as the sole arbiter of judgement.

What follows, then, is a methodically dense account of how the pragmatic sociology of critique views the 'social world as the scene of a trial' (25) where competing actors mobilise critical positions in order to resolve disputes. In practice this involves the positing of a self-contained sociological vocabulary of affairs, scandals, worlds, realities, realities of realities, truth, reality and existential tests, rituals, collectives and metacritiques. This system-which accounts for the ways in which actors come to recognise prejudice, question the reality of reality and form collectives to overcome fragmentation and thereby enact social change-well demonstrates the attraction but also the potential exhaustion induced by this form of system building and at times the level of abstraction can obscure particular events and actors I feel Boltanski might be gesturing towards. However, the overwhelming rush of exposition can be understood in part as a symptom of Boltanski's own impatience with this method, as his account sets the scene for his complaint that although the sociology of critique can acknowledge the critical capacity of actors, it lacks the wider critical potential of critical sociology to question the very forms of reality.

Boltanksi's search for a compromise between the sweeping alternatives offered by critical sociology and the limited, but more subtle, social accounts furnished by the sociology of critique thus set the theoretical scene for the remainder of $O n$ Critique, where Boltanski furnishes a pragmatic critical theory based around a third interdependent opposition of critique and the institution. As alluded to earlier, the institution is identified by Boltanski as a foundational, but under-thought, aspect of sociology understood as an everyday aspiration towards objectivity that may be secured by attaining a bodiless state. Whereas embodied beings are bound by points of view, institutions can feign to offer unbiased accounts of the world, and thereby to act as the final arbiters of truth in disputes between the partial perspectives of particular subjects. Working through spokespersons, institutions thus work to confirm their view of reality or the 'whatness of what is', (55) acting as stabilising epistemological forces that by means of repeated rituals define language, categories, narratives and logics by which to understand the world. The institution should by no 
means be thought of as benign, however, and the stable orders they offer are almost inevitably orders of domination and exploitation.

Boltanski offers the countervailing force of critique as the means to undercut the stabilising role of institutions. Arising out of a shared perception of injustice, an existential sense of unease and suffering or the failure of an institution's account of the world to match its actual existence, critique transgresses the boundaries set by dominant institutions, and owns that transgression as a deliberate challenge. In this conception, institutions stand for a timeless, static view of reality, whereas critique arises from the perspective of a changing world, in a manner somewhat akin to Michel de Certeau's opposition of strategies and tactics. Locked in this arrangement, the domination of the institution is never total and complete, but always remains open to the possibility of critique by virtue of its fragile and ultimately ungrounded authority. At the same time, neither is pure critique desirable, because institutions provide the common stability necessary for a society to develop, communicate and survive in the first instance. Critique and the institution are thus bound to one another, a point that emerges even more strongly in Boltanski's final considerations regarding the role of critique under managerial capitalism.

The central operation of Boltanski's final opposition-which emerges between simple and complex domination-is change. Change describes the fundamental nature of the world, against which institutions oppressively and impossibly struggle. But change also describes the nature of domination itself, which shifts over time. Whereas simple domination seeks to establish a single static and correct state of the world policed by experts, contemporary capitalist societies are marked by the existence of complex domination that seeks to manage, rather than deny, change. In this world, everything is ostensibly open for discussion, actors harbour no illusions about their situation and asymmetries are maintained through the constant reinterpretation of the shifting world. Under such conditions, the power to determine reality is controlled by experts who frame their interventions into reality as minor changes divorced from value calculations. Dominant institutions no longer bother to provide their perspective of the world, but collapse the distance between the world and their perspective in their quest to let circumstances apparently beyond their control dictate their behaviour: producing a new state with no distinction between physical world and epistemological reality, for which Boltanski 
coins the neologism 'wol\&real'. (137) Under the system of managerial capitalism, old tactics and means of critique now no longer prove potent and it therefore becomes necessary to revive old and form new modes of critique: not least those that recognise it is not systems that dominate and exploit, but always particular groups of people, even when such groups are difficult to perceive. Boltanski concludes with a call to refashion critique against capitalist exploitation by dominant groups, rather than abstract structures of power and institutions tout court. While recognising the constant potential for institutions to oppress and dominate, Boltanski argues that they will always remain necessary for a shared social existence. Therefore, critique should not be understood as the inevitable opponent of institutions, but rather should aim to exist alongside them in a way that balances and controls their excesses, reveals their fragility and acts to generate and justify a responsibly imbalanced society that can move beyond capitalism.

At turns enlighteningly lucid and stultifying dense, On Critique constitutes a careful, considered attempt to lay bare some of the central assumptions of contemporary critical practice and its relation to politics. If it is at times a difficult path to follow, this is in no small part the price to pay for doing so in a scholarly judicious and vigilant manner. Indeed, this is a form of sociology that never took its eye off a certain exactness of methodology that emerges in a long-form clarity of writing, repeated exposure to which can prove inspiring and soporific in equal measure. Such an approach, though, is almost the necessary price to pay in attempting the necessary and ultimately rewarding work of unpacking a term that lies at the root of much contemporary scholarship. While the dogged nature of Boltanski's analysis leads him away from and over some potentially useful avenues of inquiry, and at times one is dimly aware of other possibilities lost in this steady and methodical treatment of the subject, this volume constitutes a remarkably useful point from which to begin an exciting and overdue conversation about the relation of culture, politics and critique.

Nicholas Holm is a PhD candidate in English and Cultural Studies at McMaster University in Canada. His research interests include media humour, popular conceptions of dissent and resistance and the politics of mass aesthetics. 